\title{
Research on Identification and Suggested Control Value of Continuous Multi-Wave Track Alignment Irregularities in High-Speed Railway
}

\author{
Fei YANG, Jialin SUN ${ }^{1}$, Yu ZHANG, Liandong LI, and Yiyu LONG \\ Infrastructure Inspection Research Institute, China Academy of Railway Sciences \\ Corporation Limited, Beijing, 100081
}

\begin{abstract}
Continuous multi-wave irregularity can easily lead to train vibration, which will influence the safety and comfort of vehicle. Due to the influence of bridge creep and track plate deformation, continuous multi-wave irregularity has appeared in high-speed railway lines, but the management value of continuous multi-wave irregularity is not given in the geometric dynamic detection standard of high-speed railway tracks in China at present. Therefore, it is necessary to continue to improve the standard. Based on the dynamic detection data of high-speed railway, the typical characteristics of continuous multi-wave track alignment irregularity are extracted, its automatic recognition model is established, and the amplitude distribution and variation trend of continuous multi-wave track alignment irregularity were statistically analyzed. The vehicle-track coupling dynamic model is established, and the relationship between continuous multi-wave track alignment irregularity and vehicle dynamic response is simulated and analyzed. The control limit of continuous multi-wave track alignment irregularity at different speed levels of high-speed railway in China are put forward.
\end{abstract}

Keyword. High-speed railway, track irregularity, continuous multi-wave irregularity, automatic recognition model, suggested control value

\section{Introduction}

The track geometric irregularity, the most important type of wheel-track excitation, is the main cause leading to vehicle system vibration [1]. Studies have found that continuous multi-wave irregularity is more likely to give rise to vehicle system vibration, which is more unfavorable to driving safety and riding comfort. At present, only the requirement of "avoiding the occurrence of continuous multi-wave irregularity" is set out in China's high-speed railway track geometric dynamic detection criteria, and no corresponding control value is given. Practical experience shows that continuous multi-wave irregularity will inevitably appear in the operating high-speed railway lines. For example, the continuous multi-wave longitudinal irregularity caused by bridge creep, track slab deformation and other reasons is no longer rare. The continuous multi-wave alignment irregularity also frequently appears in recent years. The alignment irregularity waveform formed by long-term operation of high-speed

\footnotetext{
${ }^{1}$ Corresponding Author, Jialin SUN, E-mail: 523296282@qq.com.
} 
railways is different from the past. Some lines are featured by short wavelength of multi-wave irregularity and periodicity. However, these circumstances were not taken into account while formulating corresponding criteria, therefore, it is necessary to further supplement and perfect the geometric management standard of high-speed railway track.

HAN Qingqiang [2], et al. investigated the relationships between multi-wave irregularity amplitude, wave number, wavelength and vehicle body acceleration by using sinusoidal waveform. Although the suggested control value of multi-wave irregularity is given, it only covered $100-200 \mathrm{~km} / \mathrm{h}$ lines. And the suggested control value of multi-wave irregularity at higher speed level is not given. WANG Zhijian [3], et al. found that continuous small track alignment and small longitudinal have great impacts on vehicle stability in a certain section during the joint commissioning and testing of Wuhan-Guangzhou High-Speed Railway, with the stationarity being 2.87. In the later stage, they carried out a comprehensive tight adjustment for this section, and also proposed to formulate the power spectral density evaluation indexes with regard to irregularity wavelength and amplitude of China's high-speed railway track, to provide a scientific basis for the tight adjustment and maintenance of ballastless track. LI Dongsheng [4], et al. made an analysis of the impact of track periodic irregularity on the simply-supported beam bridge of high-speed railway with a common span, and found that track periodic irregularity mainly affects the longitudinal standard deviation and vertical acceleration. To this end, they proposed to set a back precamber to eliminate the impact of track periodic irregularity. LIU Jinzhao [5] proposed a diagnosis and evaluation method of track periodic geometric irregularity based on the continuous multi-wave and generalized energy method describing the hunting instability of bogie, and raised to use generalized energy index to evaluate the state of periodic geometric irregularity. SONG Guohua [6], et al. made an analysis of the causes of periodic track longitudinal irregularity on $32 \mathrm{~m}$ simply-supported box girder of high-speed railway, and investigated its impact on the dynamic performance of vehicles and bridges, and proposed the suggested limit value of girder creep camber when the train speed is $300-350 \mathrm{~km} / \mathrm{h}$.

Most of the above literatures only made a quantitative study on the relationship between continuous multi-wave irregularity of high-speed railway and vehicle response, and did not propose the corresponding control value. At present, the vast majority of the studies on continuous multi-wave track irregularity mainly focus on the longitudinal irregularity, and there are few studies on the typical characteristics and impact law of continuous multi-wave alignment irregularity. Due to the existence of many nonlinear components in the vehicle suspension system, such as lateral damper, the correlation between continuous multi-wave track alignment irregularity and vehicle response is more complex and harmful. Due to the lack of sampling of actual continuous multi-wave irregularity in previous studies, the hypothetical sine wave or cosine wave was adopted basically. As a consequence, the mastery of typical wavelength coverage, amplitude change trend and recognition method of multi-wave track is insufficient. Therefore, the study on the geometric characteristics of multi-wave track alignment irregularity samples and their correlation with vehicle dynamic response is in badly needed. In this paper, the typical geometric characteristics of continuous multi-wave track irregularity and the suggested value of measurement control are proposed by means of time-frequency domain analysis of dynamic detection data and dynamic simulation, so as to provide technical support for on-site maintenance and repair work. 


\section{Provisions of Other Countries on Multi-wave Irregularity}

The typical characteristics of continuous multi-wave irregularity include similar waveform, same fundamental wavelength, coverage of other wavelength components as well as random amplitude. As can be seen from the conversion relationship between wavelength, speed and frequency, when the continuous multi-wave length is close to the vehicle sensitive frequency at a certain speed, the vehicle will produce violent periodic vibration. Foreign track managers have long recognized the harm of multi-wave irregularity. For example, EN13848-5 indicates that continuous deviation should be taken into consideration when evaluating track geometric quality, because it may produce resonance effect [7]. British line managers hold that continuous multi-wave irregularity will increase the risk of derailment. When the measured track irregularity is repeated at a certain frequency, it will cause harmonic response of vehicle suspension. In case of long continuous multi-wave irregularity, energy will accumulate in suspension and even lead to derailment. Therefore, British standards stipulate that the maintenance time shall be shortened in case of continuous multi-wave irregularity [8]. American and French standards set out the standard values [9] of single-wave irregularity and multi-wave irregularity, respectively, as shown in Table 1.

Table 1. Single-wave and Multi-wave Irregularity Control Standards in the US and France

\begin{tabular}{|c|c|c|c|c|c|c|c|c|}
\hline & \multicolumn{2}{|l|}{ France } & \multicolumn{6}{|c|}{ The US (Safety Standards) } \\
\hline & $\begin{array}{l}\text { Longitudi } \\
\text { nal }\end{array}$ & $\begin{array}{l}\text { Track } \\
\text { Alignm } \\
\text { ent }\end{array}$ & $\begin{array}{l}\text { Longitudi } \\
\text { nal }\end{array}$ & $\begin{array}{l}\text { Track } \\
\text { Alignm } \\
\text { ent }\end{array}$ & $\begin{array}{l}\text { Longitudi } \\
\text { nal }\end{array}$ & $\begin{array}{l}\text { Track } \\
\text { Alignm } \\
\text { ent }\end{array}$ & $\begin{array}{l}\text { Longitudi } \\
\text { nal }\end{array}$ & $\begin{array}{l}\text { Alignm } \\
\text { ent }\end{array}$ \\
\hline $\begin{array}{l}\text { Span } \\
(\mathrm{m})\end{array}$ & $31 \mathrm{~m}$ & $33 \mathrm{~m}$ & \multicolumn{2}{|l|}{$37.8 \mathrm{~m}$} & \multicolumn{2}{|l|}{$9.4 \mathrm{~m}$} & $9.4 \mathrm{~m}$ & $9.4 \mathrm{~m}$ \\
\hline $\begin{array}{l}\text { Contr } \\
\text { ol } \\
\text { Value } \\
(\mathrm{mm})\end{array}$ & $10 / 8$ & $12 / 8$ & $19 / 13$ & $32 / 22$ & $13 / 10$ & $13 / 10$ & $13 / 10$ & $19 / 13$ \\
\hline $\begin{array}{l}\text { Speed } \\
\text { Level } \\
(\mathrm{km} / \mathrm{h} \\
\end{array}$ & \multicolumn{2}{|l|}{ Above 160} & \multicolumn{4}{|l|}{354} & \multicolumn{2}{|l|}{257} \\
\hline
\end{tabular}

Note: The upper limit value of "/" is a single irregularity limit, and the lower one is three continuous non-overlapping irregularity limits.

\section{Characteristics of Multi-wave Track Alignment Irregularity}

Figure 1 shows the dynamic detection waveform of track alignment irregularity of a certain high-speed railway in operation. As can be seen from the figure that the characteristics of continuous periodic multi-wave track alignment irregularity are very obvious. In order to investigate the wavelength characteristics of track alignment irregularity, short-time Fourier transform (STFT)[10-13] is adopted in this paper, which can simultaneously obtain the distribution of signal energy with time and frequency. STFT is defined as follows:

Given the square-integrable signal $\mathrm{x}(\mathrm{t})$, assuming that $\mathrm{x}(\mathrm{t})$ is stable in the window function $\mathrm{g}(\mathrm{t})$, then the STFT[11] is defined as

$$
G(\tau, \omega)=\int_{-\infty}^{+\infty} x(t) g(t-\tau) e^{-i \omega t} d t
$$


If the window function $\mathrm{g}(\mathrm{t})$ satisfies

$$
\int_{-\infty}^{+\infty} g(t) d t=1
$$

then the signal $\mathrm{x}(\mathrm{t})$ can be reconstructed by the inverse STFT transform. The inverse transform formula is

$$
x(t)=\frac{1}{2 \pi} \int_{-\infty}^{+\infty} \int_{-\infty}^{+\infty} G(\tau, \omega) e^{+i \omega t} d \tau d \omega
$$

According to the above definition, STFT can reveal the time-varying characteristics of each frequency component of the signal through introducing a window function. In this paper, Hamming is often used, and the track time-frequency diagram of K18-K20 sections is as shown in Figures 1-3. As can be seen from the figure that energy peaks appear in K18+100 - 300, K19 - K19+100, K19+200 $\mathrm{K} 19+500$ and K19+700 - K19+500 sections, with peak frequency of $0.11-0.13 \mathrm{~m}-1$ and corresponding wavelength of $7-10 \mathrm{~m}$.

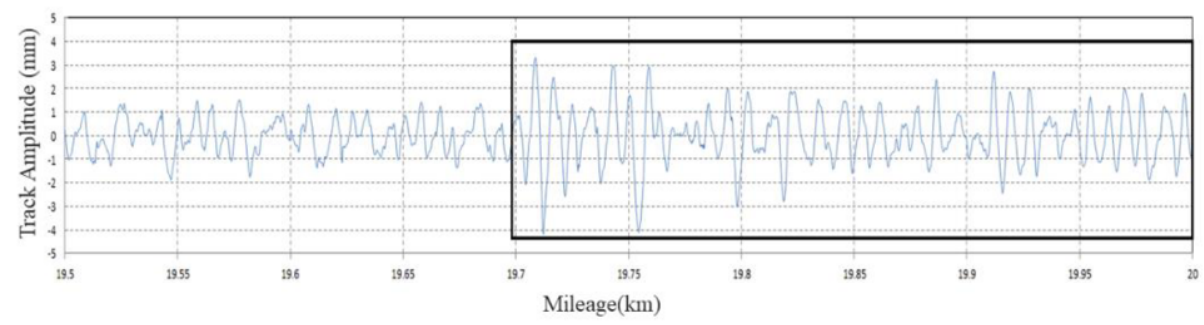

Figure 1. Waveform of Track Alignment Irregularity

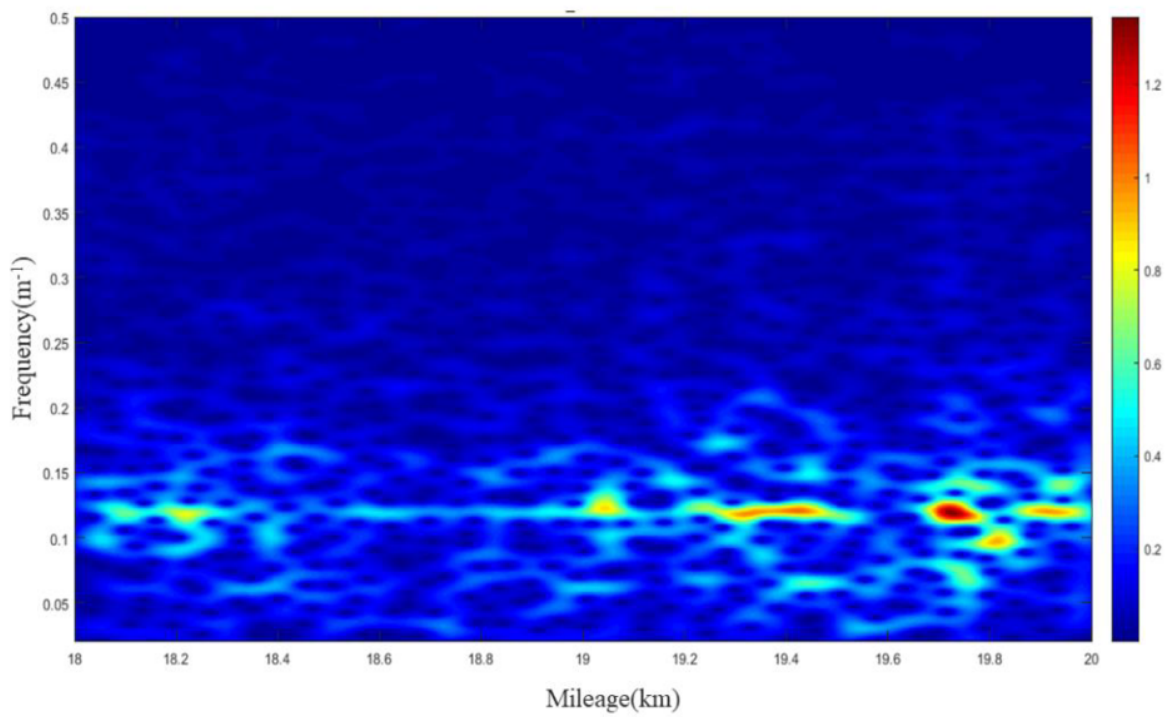

Figure 2. Time-Frequency Analysis of Track Alignment Irregularity 


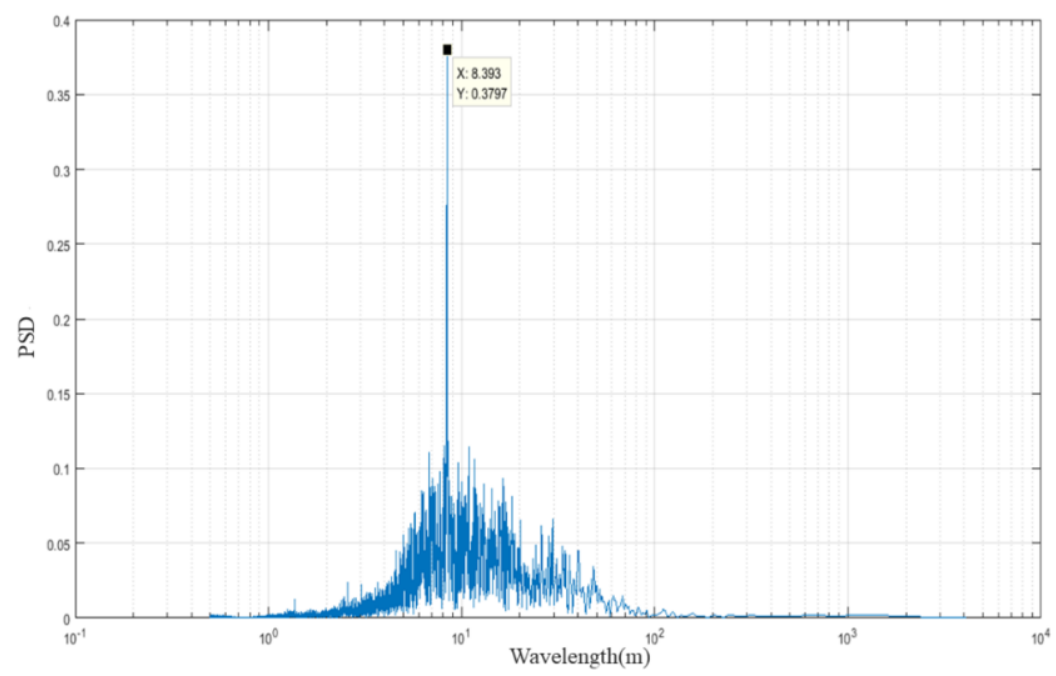

Figure 3. Frequency Spectrum of Track Alignment Irregularity

According to the frequency spectrum analysis of track irregularity, the wavelength of periodic multi-wave track alignment irregularity generally ranges from $7 \mathrm{~m}$ to $10 \mathrm{~m}$. According to the investigation, the continuous periodic track irregularity in the long section is very likely to be caused by the failure to timely supplement the ballast and adjust the track in some sections after rail laying in the construction stage, which leads to the fact that long rail vehicles, ballast unloading vehicles and other engineering trains have to run on poor track which are in bad condition of alignment and longitudinal. As a consequence, lateral periodic hard bending of steel rails is formed, and such problem is hard to solve just by tamping. The site review photo is as shown in Figure 4.
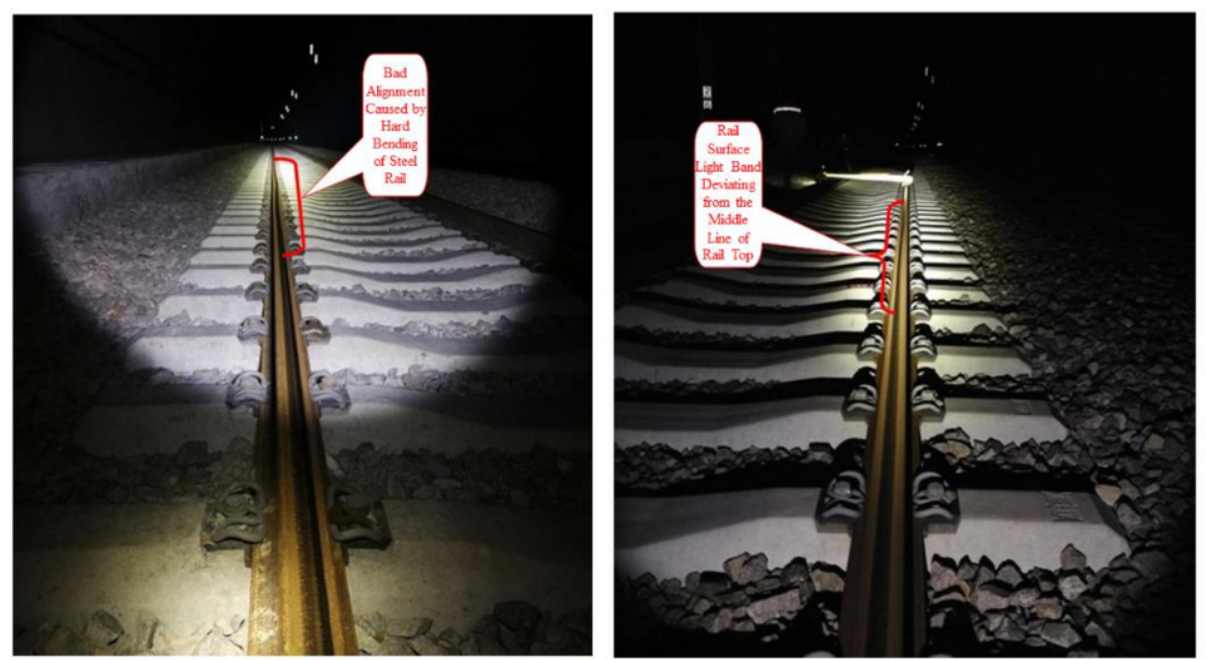

Figure 4. Site Review of Continuous Periodic Track Alignment Irregularity 


\section{Recognition of Multi-wave Track Alignment Irregularity}

Based on the above track alignment irregularity characteristics, a recognition model is established to recognize the continuous multi-wave track alignment irregularity of a certain line. The detailed recognition process is as follows: (1) Obtain the track alignment detection data of multi-purpose maintenance car; (2) Extract all the peak points of the track alignment data, record their amplitude and mileage, and then screen out peak points with the peak value smaller than $0.2 \mathrm{~mm}$; (3) Identify the section with a continuous peak value greater than $1.2 \mathrm{~mm}$, with some points in the middle not meeting the conditions allowed; (4) Calculate and identify the peak value of all wave peaks in the section, and eliminate the section with a peak value smaller than $1.5 \mathrm{~mm}$; (5) Calculate the mileage difference between the wave peaks, and screen out the section of which the mileage difference is more than 30\%; (6) Make a frequency spectrum analysis of suspected sections, and extract the section with more concentrated principal component frequency.

According to the above recognition model, the periodic track alignment irregularity section of this line is automatically found, as shown in Figure 5. A total of $1.476 \mathrm{~km}$ lines with continuous multi-wave track irregularities are identified, and cumulative distribution is carried out for the peak values of periodic track irregularities, as shown in Figure6. As can be seen from the cumulative distribution diagram that the cumulative distribution of dynamic amplitude values in the left and right track alignment of the line is basically the same, and that of the right track alignment is slightly higher, wherein $50 \%$ quantile amplitude of the right is $1.24 \mathrm{~mm}, 90 \%$ quantile amplitude is $2.38 \mathrm{~mm}$, and $95 \%$ quantile amplitude is about $2.81 \mathrm{~mm}$.

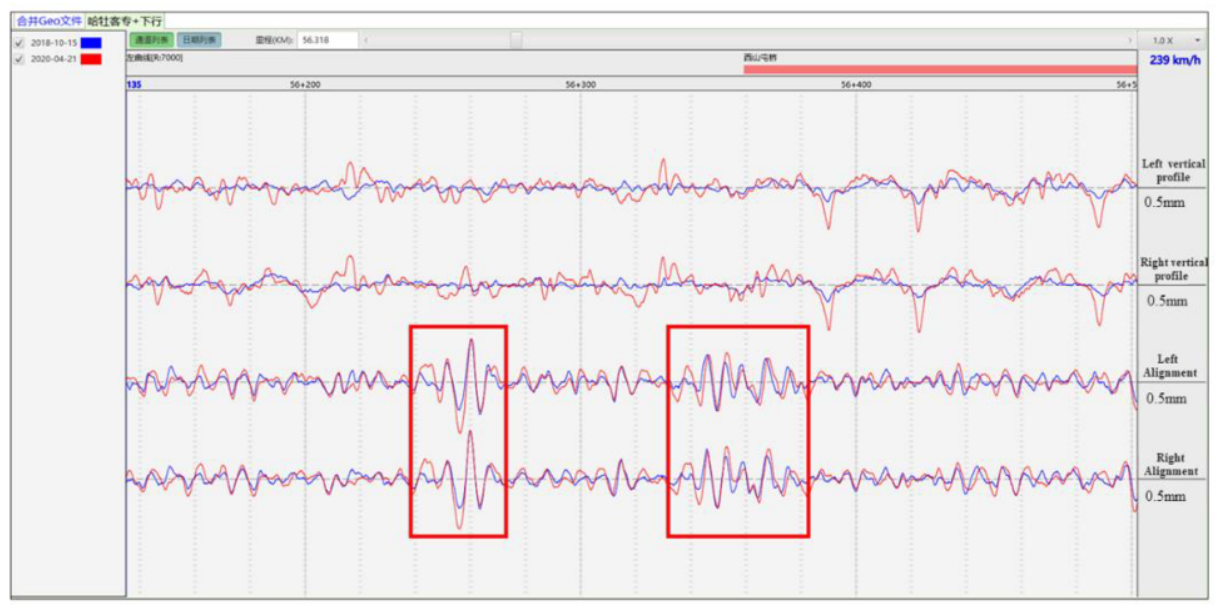

Figure 5. Search Results of Periodic Track Alignment Irregularity Section of a Certain Line 


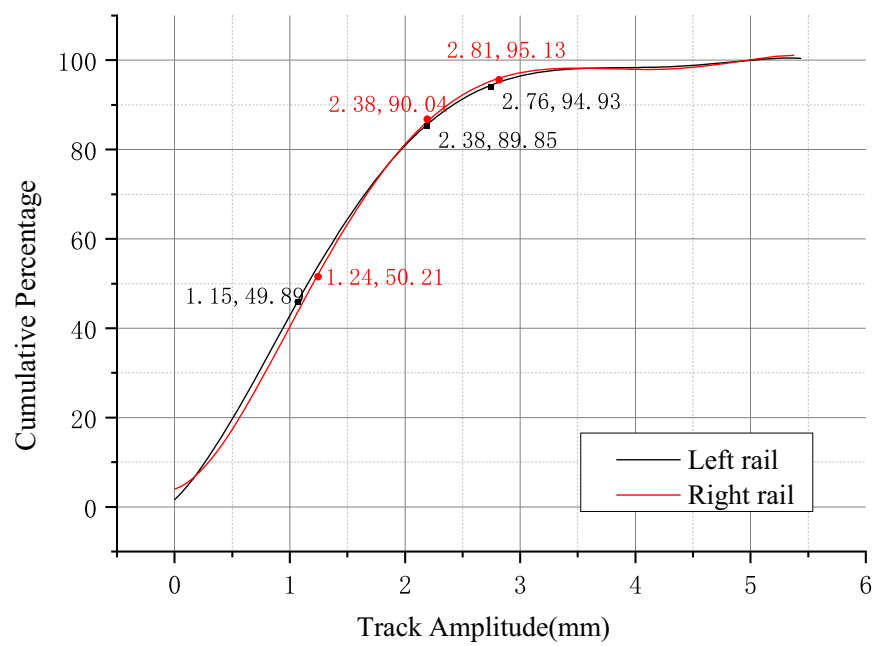

Figure 6. Cumulative Distribution of Amplitude Values in Periodic Track Alignment Irregularity Section of a Certain Line

According to the survey, the line went into operation in October 2018, and the detection data at that time were compared with that in April 2020. The cumulative distribution of variations in periodic track alignment irregularity section is as shown in Figure7. As can be seen from Figure 6 that the variation of left track alignment is slightly higher than that of right track. After operating for 18 months, the track alignment variation of $50 \%$ quantile is increased by $0.36 \mathrm{~mm}$, that of $90 \%$ quantile by $1.16 \mathrm{~mm}$, and that of $95 \%$ quantile by $1.38 \mathrm{~mm}$. The maximum amplitude of continuous multi-wave track alignment irregularity reaches $3.5 \mathrm{~mm}$, and shaking and poor light band also occur in some sections. The results show that continuous multi-wave irregularity develops at a faster rate, and it will seriously threaten the comfort and operation safety if no rectification measures are taken in time.

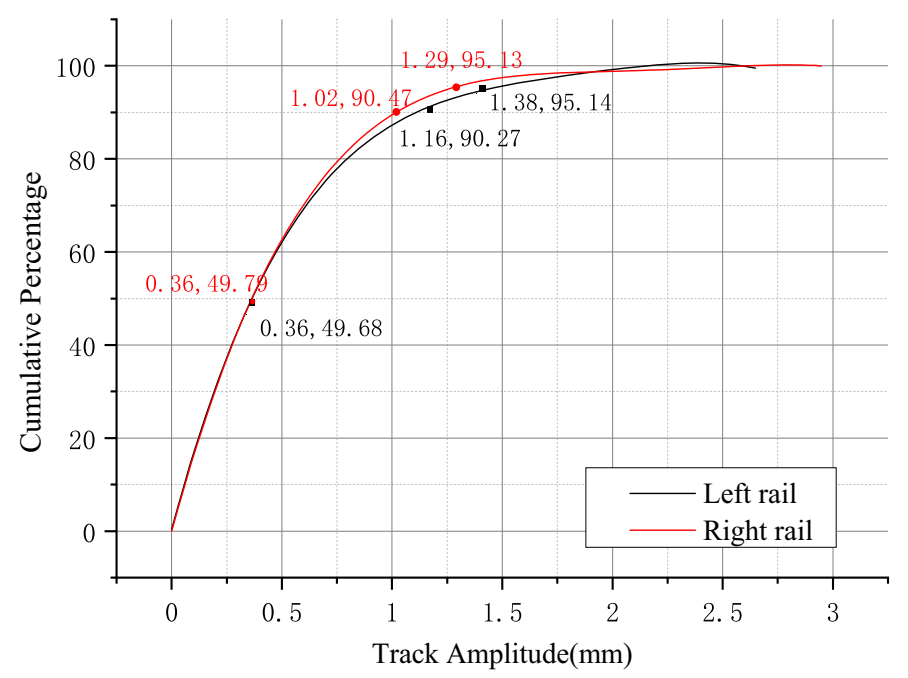

Figure 7. Cumulative Distribution of Variations in Periodic Track Alignment Irregularity Section of a Certain Line 


\section{Analysis of Control Limit of Continuous Multi-wave Track Alignment}

\subsection{Dynamic Simulation Model and Calculation Conditions}

Since the multi-wave irregularity cannot be avoided and its impact on operation comfort and safety is more serious, it is very necessary to carry out a theoretical analysis of the amplitude control requirement of multi-wave irregularity to guide the site maintenance and repair. In this paper, a high-speed EMU simulation model[15,16] is established with UM multi-body dynamic simulation software, as shown in Figure 8. $200-250 \mathrm{~km} / \mathrm{h}$ EMUs and $300-350 \mathrm{~km} / \mathrm{h}$ EMUs are used for the dynamic simulation analysis to obtain the control limit of continuous multi-wave track alignment irregularity of lines in different speed levels.

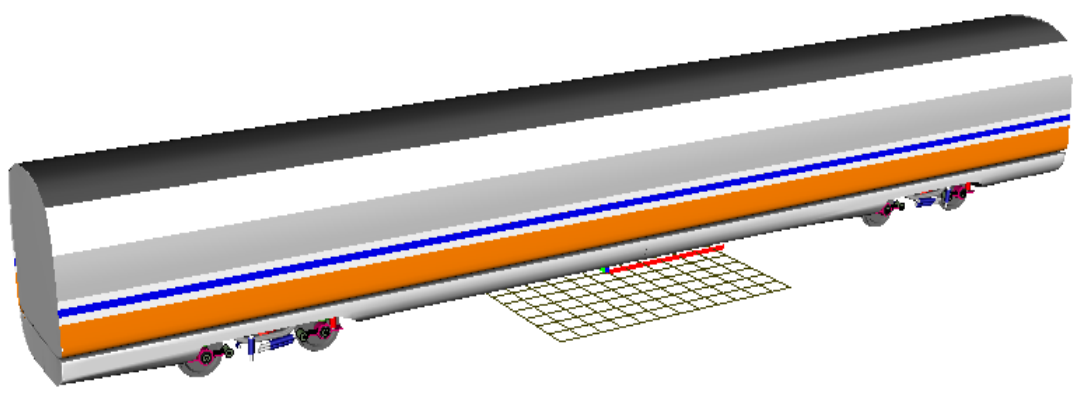

Figure 8. Vehicle Simulation Model of High-speed EMU

By taking the track alignment irregularity of three consecutive $10 \mathrm{~m}$-wavelength as example, the impact of continuous multi-wave track irregularity on vehicle dynamic response is analyzed in this paper. The comparison of waveforms of lateral acceleration of vehicle body under single-wave and multi-wave conditions is as shown in Figure 9. As can be seen from the waveform graph that, due to the impact of center distance, wheel base and multi-wave irregularity wavelength of bogie, the continuous multi-wave irregularity may have larger dynamic response compared with the single-wave condition, which intensifies the vehicle vibration.

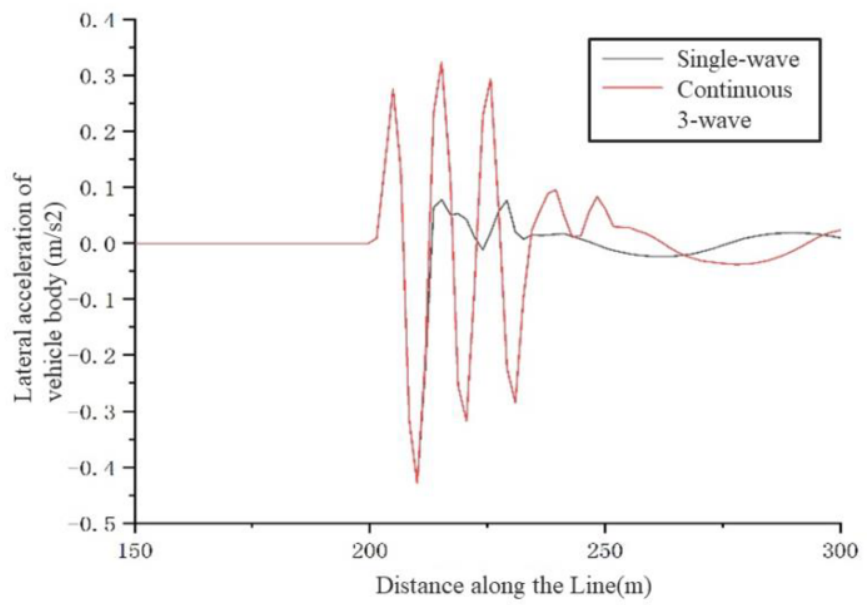

Figure 9. Impact of Continuous Multi-wave Action on the Lateral Acceleration of Vehicle Body 
In order to analyze the correlation between continuous multi-wave track alignment irregularity and vehicle dynamic response, for $200-250 \mathrm{~km} / \mathrm{h}$ ballasted lines, $250 \mathrm{~km}$ ballasted track irregularity spectrum is selected for track vertical vibration, and $250 \mathrm{~km}$ ballasted track irregularity spectrum and consecutive 10 sine-wave track irregularity are selected for lateral excitation. For $300-350 \mathrm{~km} / \mathrm{h}$ ballasted lines, $350 \mathrm{~km}$ ballastless track irregularity spectrum is selected for track vertical excitation, and $350 \mathrm{~km}$ ballastless track irregularity spectrum and consecutive 10 sine-wave track irregularity are selected for lateral excitation. According to the previous dynamic test data analysis and the site static measurement result, the peak interval of track irregularity mainly includes $7 \mathrm{~m}$ and $10 \mathrm{~m}$.

The dynamic evaluation indexes include: derailment coefficient: $\leq 0.8$; lateral acceleration of vehicle body: $\mathrm{aL} \leq 0.06,0.09 \mathrm{~g}, 0.15 \mathrm{~g}$ and $0.2 \mathrm{~g}$ (correspond to the four-level management standard of irregularity); lateral acceleration filter frequency of frame: $0.5-10 \mathrm{~Hz}$. When the peak value reaches or exceeds $8 \mathrm{~m} / \mathrm{s} 2$ for more than 6 consecutive times, it can be judged that the bogie is unstable; wheel-axle lateral force: $\leq 53 \mathrm{kN}$. The correlation between vehicle dynamic response and amplitude is analyzed by changing the continuous multi-wave track alignment irregularity. When the dynamic index reaches or gets close to the above limit, the increase of track irregularity stops, and the current amplitude is used as the control requirement.

\section{$5.2200-250 \mathrm{~km} / \mathrm{h}$ Ballasted Track}

(1) $7 \mathrm{~m}$ peak interval

Figure 10 to Figure 13 show the change trend of such dynamic indexes as derailment coefficient, lateral acceleration of vehicle body, lateral acceleration of frame and wheel-axle lateral force with the track alignment irregularity amplitude and running speed at the peak interval of $7 \mathrm{~m}$. It is observed that, under the excitation of continuous multi-wave track alignment at the peak interval of $7 \mathrm{~m}$, the above dynamic indexes all increase gradually with the increasing track alignment irregularity amplitude.

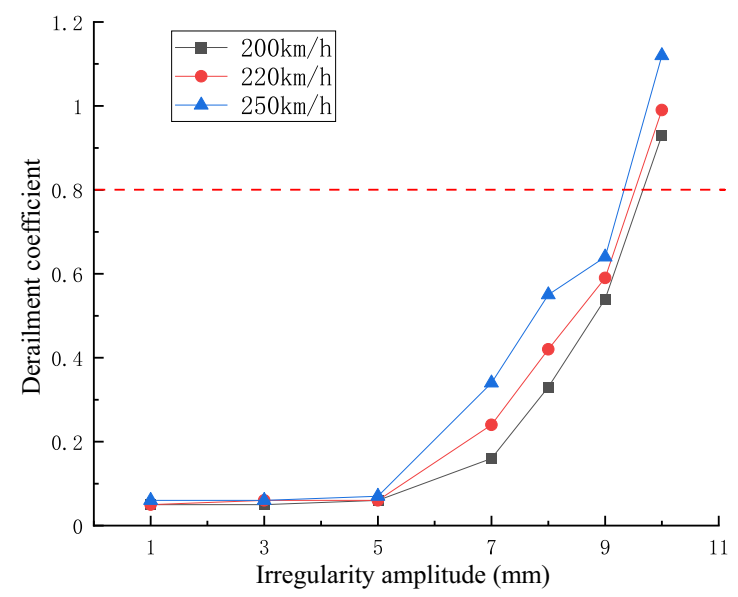

Figure 10. Change Trend of Derailment Coefficient with Irregularity Amplitude 


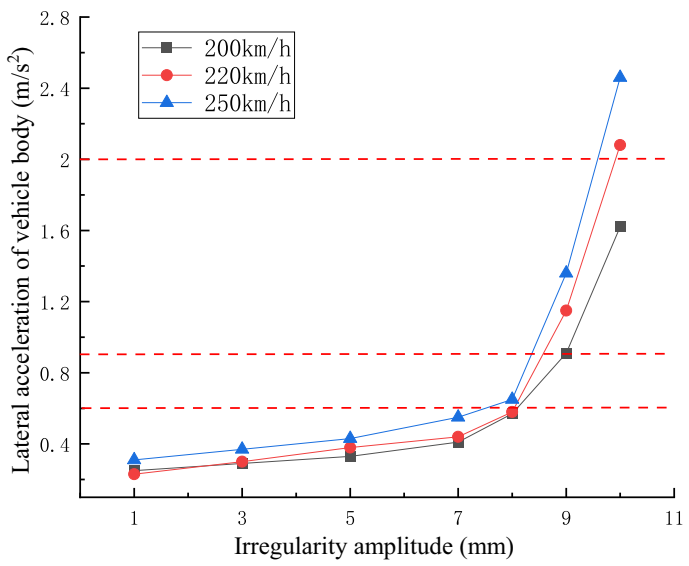

Figure11. Change Trend of Lateral Acceleration of Vehicle Body with Irregularity Amplitude

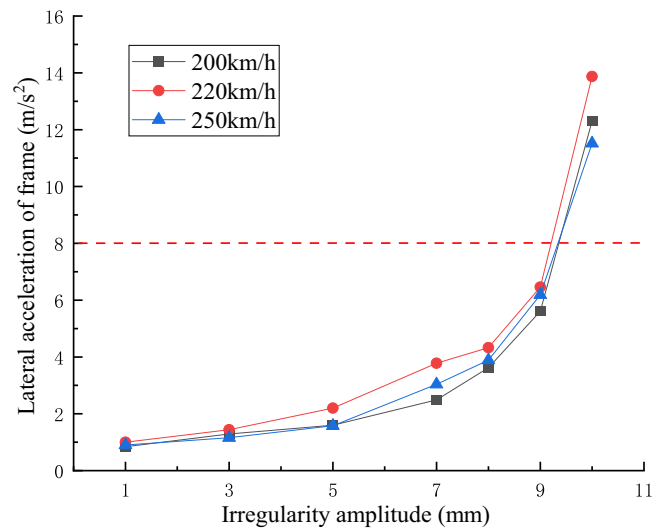

Figure12. Change Trend of Lateral Acceleration of Frame with Irregularity Amplitude

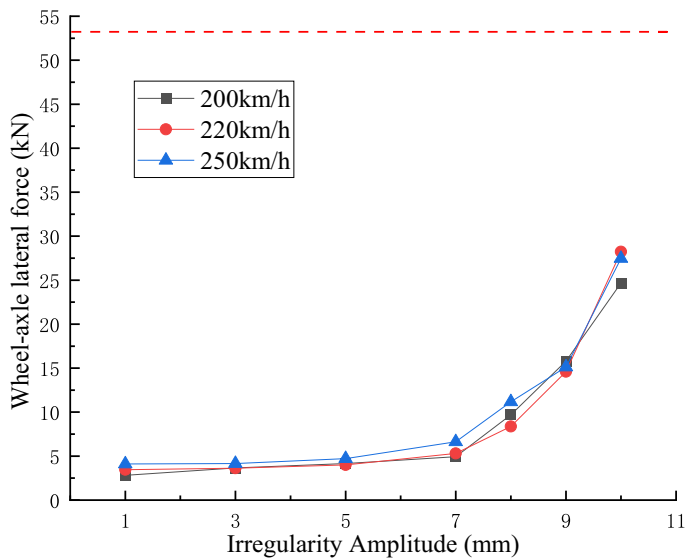

Figure13. Change Trend of Wheel-axle Lateral Force with Irregularity Amplitude 
As can be seen from Figure 10 to Figure 13 that, when the speed of vehicle is $200-250 \mathrm{~km} / \mathrm{h}$, the irregularity amplitude reaches $8 \mathrm{~mm}$ (half peak), and the lateral acceleration of vehicle body reaches about $0.06 \mathrm{~g}$; the irregularity amplitude reaches [8,9]mm (half peak), and the lateral acceleration of vehicle body reaches about $0.09 \mathrm{~g}$; the irregularity amplitude reaches $10 \mathrm{~mm}$ (half peak), and the derailment coefficient exceeds the safety limit 0.8 . Besides, after the irregularity amplitude exceeds $7 \mathrm{~mm}$ (half peak), all dynamic index response values show a sharp increase.

(2) $10 \mathrm{~m}$ peak interval

Figure 14 to Figure 17 show the change trend of such dynamic indexes as derailment coefficient, lateral acceleration of vehicle body, lateral acceleration of frame and wheel-axle lateral force with the track alignment irregularity amplitude and running speed at the peak interval of $10 \mathrm{~m}$. It is observed that, under the excitation of continuous multi-wave track at the peak interval of $10 \mathrm{~m}$, the above dynamic indexes all increase gradually with the increasing track alignment irregularity amplitude.

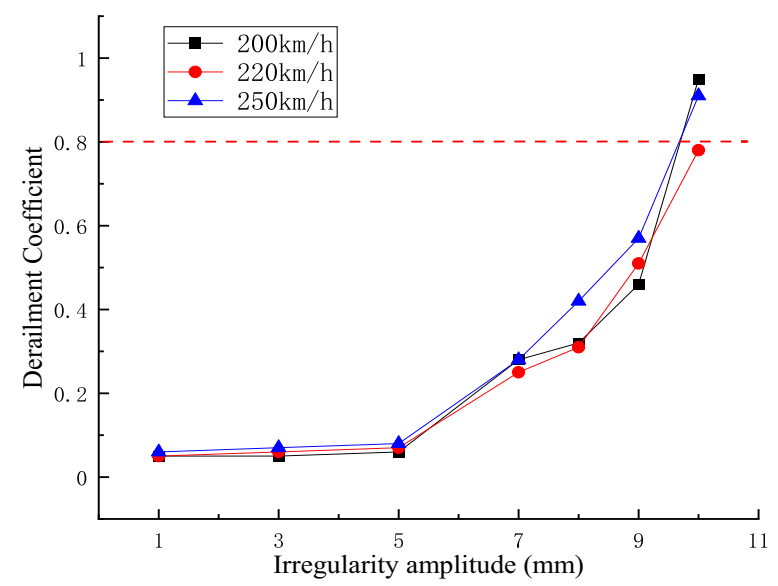

Figure 14. Change Trend of Derailment Coefficient with Irregularity Amplitude

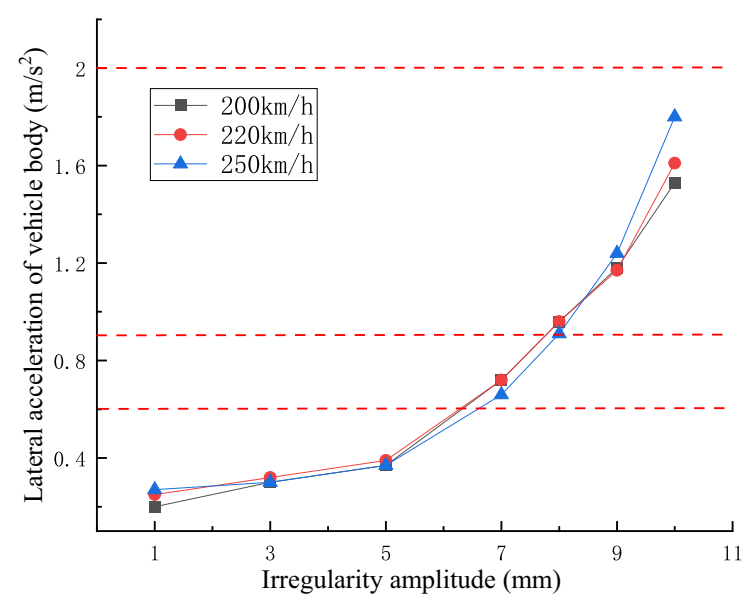

Figure 15. Change Trend of Lateral Acceleration of Vehicle Body with Irregularity Amplitude 


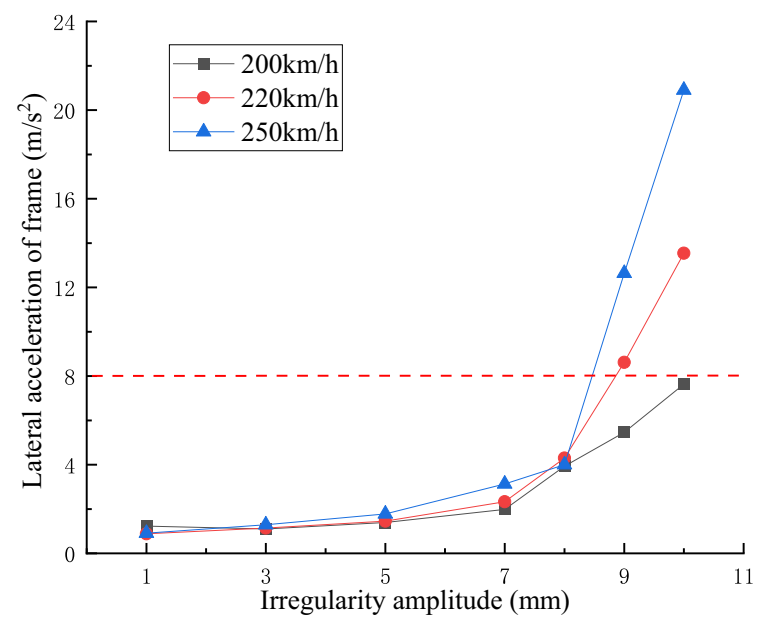

Figure 16. Change Trend of Lateral Acceleration of Frame with Irregularity Amplitude

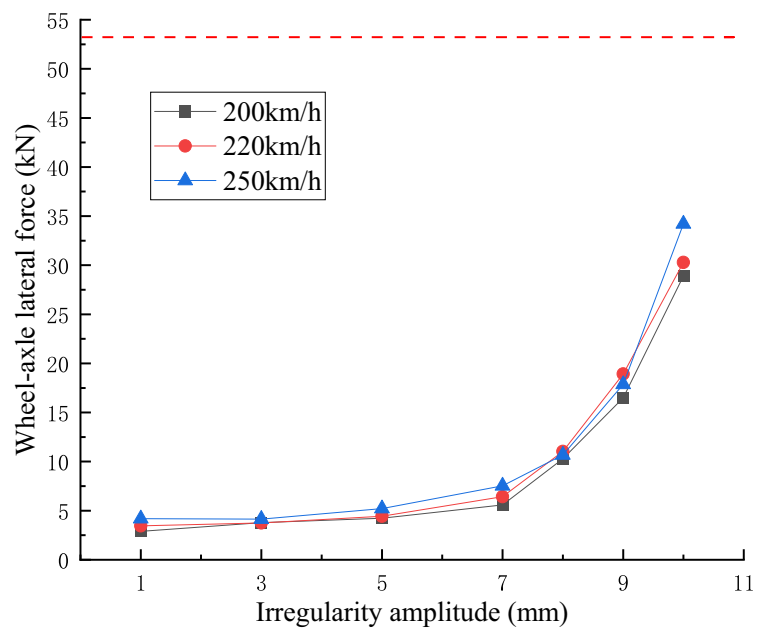

Figure17. Change Trend of Wheel-axle Lateral Force with Irregularity Amplitude

As can be seen from Figure 14 to Figure 17 that, when the speed of vehicle is $200-250 \mathrm{~km} / \mathrm{h}$, the irregularity amplitude reaches $6 \mathrm{~mm}$ (half peak), and the lateral acceleration of vehicle body reaches about $0.06 \mathrm{~g}$; the irregularity amplitude reaches $8 \mathrm{~mm}$ (half peak), and the lateral acceleration of vehicle body reaches about $0.09 \mathrm{~g}$; the irregularity amplitude reaches $10 \mathrm{~mm}$ (half peak), and the derailment coefficient exceeds the safety limit 0.8 . Besides, after the irregularity amplitude exceeds $5 \mathrm{~mm}$ (half peak), all dynamic index response values show a sharp increase.

For the speed of $200-250 \mathrm{~km} / \mathrm{h}$, the comprehensive peak interval is the simulation result of $7 \mathrm{~m}$ and $10 \mathrm{~m}$. It is found that the peak interval of $10 \mathrm{~m}$ is more sensitive to the variation of multi-wave track irregularity amplitude, and the site construction departments measure the track alignment with $10 \mathrm{~m}$ chord measuring method. Therefore, in order to ensure the safety and comfort and reserve certain redundancy, the continuous track irregularity control amplitude of $200-250 \mathrm{~km} / \mathrm{h}$ ballasted track shall be $5 \mathrm{~mm}, 7 \mathrm{~mm}$ and $9 \mathrm{~mm}$, respectively. The current speed limit standard of $200-250 \mathrm{~km} / \mathrm{h}$ 
ballasted track is $10 \mathrm{~mm}$. The simulation result indicates that continuous track alignment irregularity is more unfavorable, therefore, the section management standard shall be more stringent.

\section{$5.3300-350 \mathrm{~km} / \mathrm{h}$ Ballastless Track}

(1) $7 \mathrm{~m}$ peak interval

Figure 18 to Figure 21 show the change trend of such dynamic indexes as derailment coefficient, lateral acceleration of vehicle body, lateral acceleration of frame and wheel-axle lateral force with the track alignment irregularity amplitude and running speed at the peak interval of $7 \mathrm{~m}$. It is observed that, under the excitation of continuous multi-wave track at the peak interval of $7 \mathrm{~m}$, the above dynamic indexes all increase gradually with the increasing track alignment irregularity amplitude.

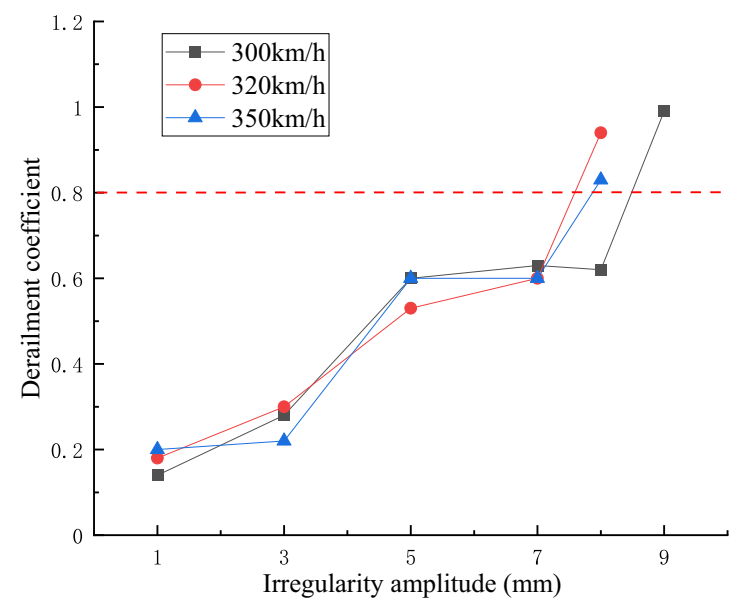

Figure 18. Change Trend of Derailment Coefficient with Irregularity Amplitude

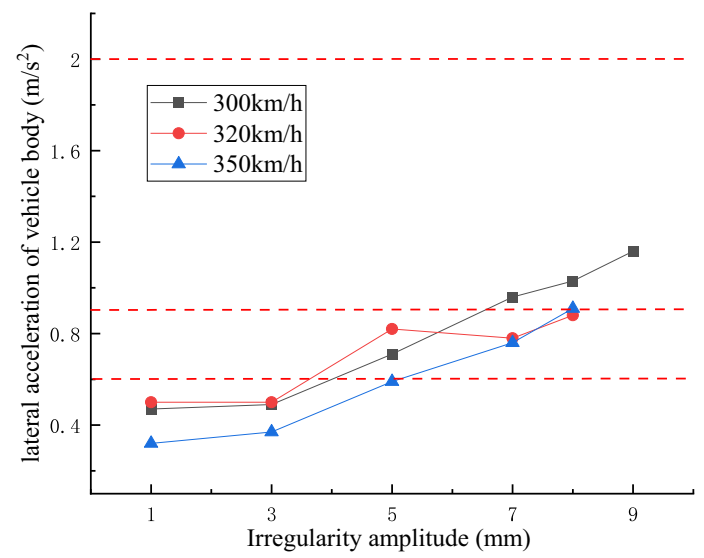

Figure 19. Change Trend of Lateral Acceleration of Vehicle Body with Irregularity Amplitude 


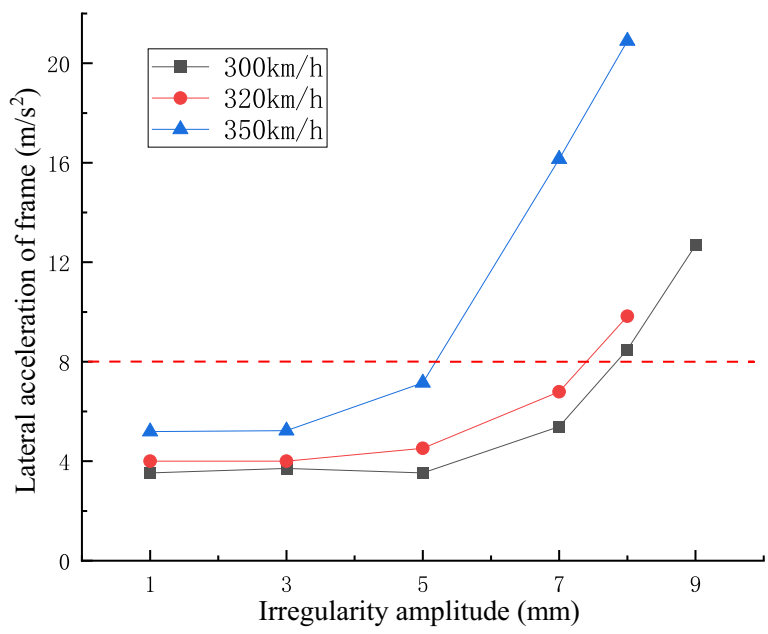

Figure 20. Change Trend of Lateral Acceleration of Frame with Irregularity Amplitude

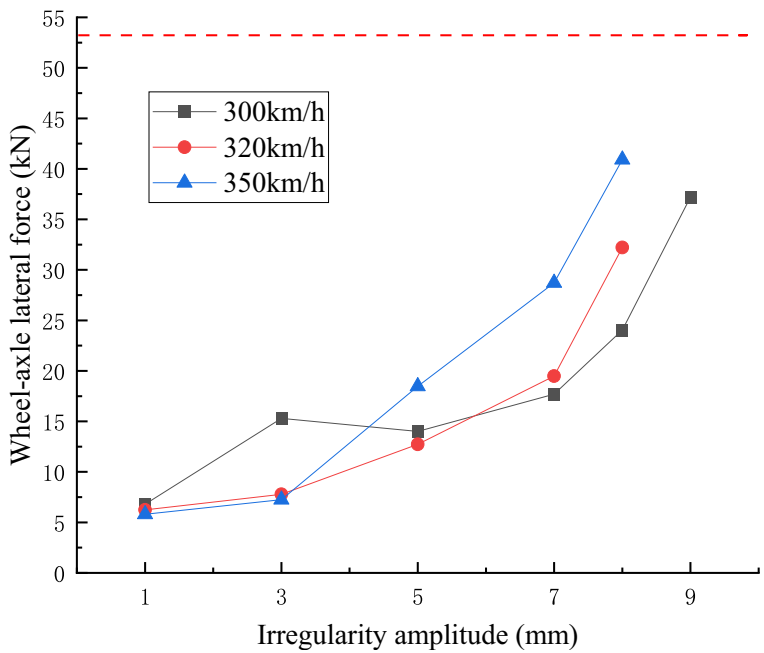

Figure 21. Change Trend of Wheel-axle Lateral Force with Irregularity Amplitude

As can be seen from Figure 18 to Figure 21 that, when the speed of vehicle is $300-350 \mathrm{~km} / \mathrm{h}$, the irregularity amplitude reaches $4 \mathrm{~mm}$ (half peak), and the lateral acceleration of vehicle body reaches about $0.06 \mathrm{~g}$; the irregularity amplitude reaches $[7,8] \mathrm{mm}$ (half peak), and the lateral acceleration of vehicle body reaches about $0.09 \mathrm{~g}$; the irregularity amplitude reaches $8 \mathrm{~mm}$ (half peak), and the derailment coefficient exceeds the safety limit 0.8 Besides, after the irregularity amplitude exceeds $3 \mathrm{~mm}$ (half peak), all dynamic index response values show a sharp increase.

(2) $10 \mathrm{~m}$ peak interval

Figure 22 to Figure 25 show the change trend of such dynamic indexes as derailment coefficient, lateral acceleration of vehicle body, lateral acceleration of frame and wheel-axle lateral force with the track irregularity amplitude and running speed at the peak interval of $10 \mathrm{~m}$. It is observed that, under the excitation of continuous 
multi-wave track alignment at the peak interval of $10 \mathrm{~m}$, the above dynamic indexes all increase gradually with the increasing track alignment irregularity amplitude.

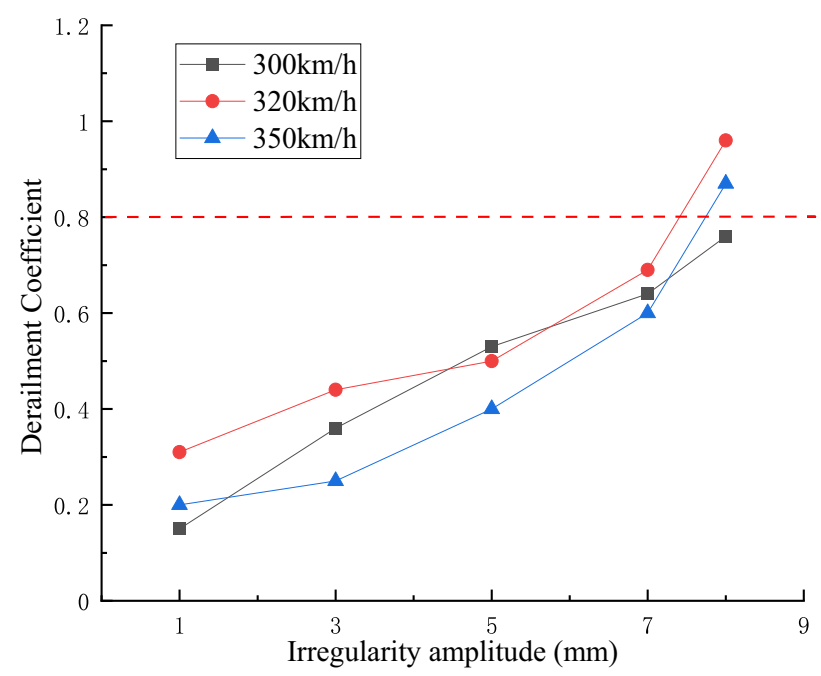

Figure 22. Change Trend of Derailment Coefficient with Irregularity Amplitude

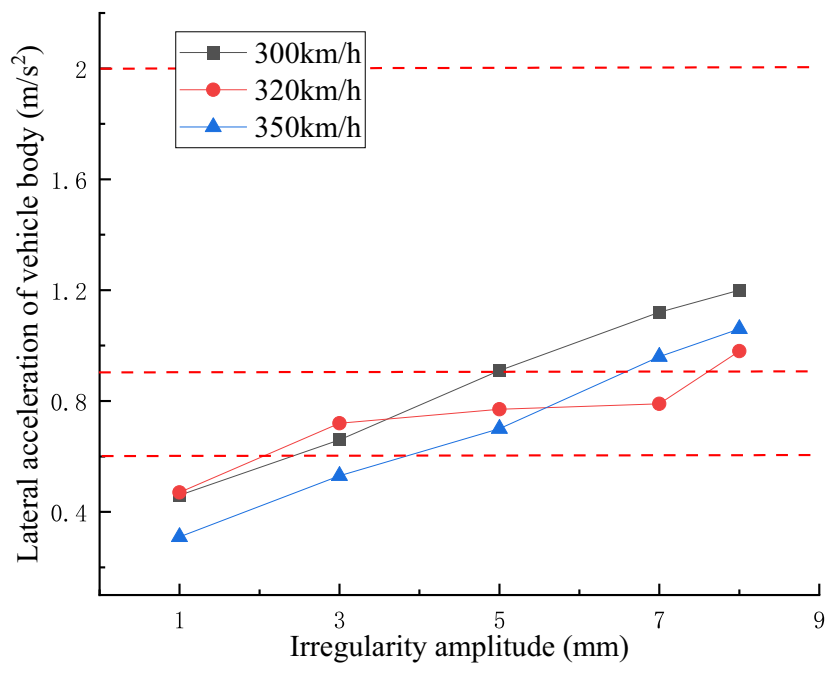

Figure 23. Change Trend of Lateral Acceleration of Vehicle Body with Irregularity Amplitude 


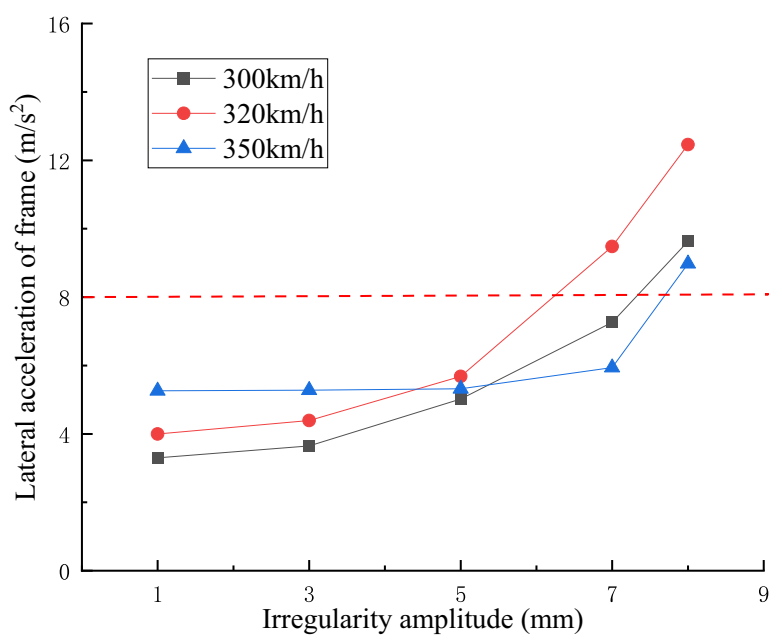

Figure 24. Change Trend of Lateral Acceleration of Frame with Irregularity Amplitude

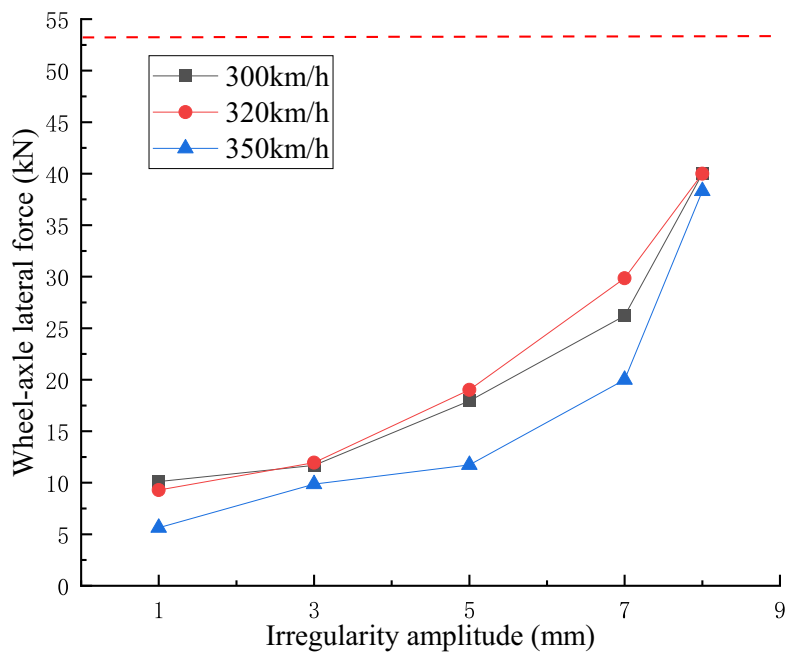

Figure 25. Change Trend of Wheel-axle Lateral Force with Irregularity Amplitude

As can be seen from Figure 22 to Figure 25 that, when the speed of vehicle is $300-350 \mathrm{~km} / \mathrm{h}$, the irregularity amplitude reaches $3 \mathrm{~mm}$ (half peak), and the lateral acceleration of vehicle body reaches about $0.06 \mathrm{~g}$; the irregularity amplitude reaches $[5,8] \mathrm{mm}$ (half peak), and the lateral acceleration of vehicle body reaches about $0.09 \mathrm{~g}$; the irregularity amplitude reaches $8 \mathrm{~mm}$ (half peak), and the derailment coefficient exceeds the safety limit 0.8 . Besides, after the irregularity amplitude exceeds $3 \mathrm{~mm}$ (half peak), all dynamic index response values show a sharp increase.

For the speed of $300-350 \mathrm{~km} / \mathrm{h}$, the comprehensive peak interval is the simulation result of $7 \mathrm{~m}$ and $10 \mathrm{~m}$. It is also found that the peak interval of $10 \mathrm{~m}$ is more sensitive to the variation of multi-wave track alignment irregularity amplitude. Therefore, in order to ensure the safety and comfort and reserve certain redundancy, the continuous track 
alignment irregularity control amplitude of $300-350 \mathrm{~km} / \mathrm{h}$ ballasted track shall be $3 \mathrm{~mm}$, $5 \mathrm{~mm}$ and $7 \mathrm{~mm}$, respectively.

According to the above simulation analysis results, the continuous multi-wave track alignment irregularity control value of high-speed railway is as shown in Table 2.

Table 2. Continuous multi-wave track alignment irregularity control value of high-speed railway

\begin{tabular}{|l|l|c|c|c|l|}
\hline $\begin{array}{l}\text { Speed } \\
\text { Level } \\
(\mathrm{km} / \mathrm{h})\end{array}$ & $\begin{array}{l}\text { Control } \\
\text { Level }\end{array}$ & $\begin{array}{l}\text { Scheduled } \\
\text { Maintenance }\end{array}$ & $\begin{array}{l}\text { Temporary } \\
\text { Repair }\end{array}$ & $\begin{array}{l}\text { Speed } \\
\text { Limit }\end{array}$ & \multicolumn{1}{c|}{ Remarks } \\
\hline 200-250 & $\begin{array}{l}\text { Track } \\
\text { Alignment }\end{array}$ & 7 & 8 & 10 & $\begin{array}{l}\text { Current regulations of } \\
\text { Maintenance Rules for } \\
\text { High-Speed Railway } \\
\text { Ballasted Track Line }\end{array}$ \\
\cline { 2 - 6 } & $\begin{array}{l}\text { Continuous } \\
\text { Multi-wave } \\
\text { Track } \\
\text { Alignment }\end{array}$ & 5 & 7 & 9 & $\begin{array}{l}\text { Suggested control value of } \\
\text { continuous multi-wave track } \\
\text { alignment irregularity }\end{array}$ \\
\hline $300-350$ & $\begin{array}{l}\text { Track } \\
\text { Alignment }\end{array}$ & 5 & 6 & 7 & $\begin{array}{l}\text { Current regulations of } \\
\text { Maintenance Rules for } \\
\text { High-Speed Railway } \\
\text { Ballasted Track Line }\end{array}$ \\
\cline { 2 - 6 } & $\begin{array}{l}\text { Continuous } \\
\text { Multi-wave } \\
\text { Track } \\
\text { Alignment }\end{array}$ & 3 & 5 & 7 & $\begin{array}{l}\text { Suggested control value of } \\
\text { continuous multi-wave track } \\
\text { alignment irregularity }\end{array}$ \\
\hline
\end{tabular}

\section{Conclusion}

(1) According to the dynamic detection waveform graph of track alignment irregularity of high-speed railway and track irregularity spectrum analysis, most wavelengths of continuous periodic multi-wave track alignment irregularity range from $7 \mathrm{~m}$ to $10 \mathrm{~m}$, the main reason is that ballast and the whole track are not supplemented timely after rail laying, long rail vehicles, ballast unloading vehicles and other engineering trains have to run on poor track which are in bad condition of alignment and longitudinal, leading to lateral periodic hard bending of rail, and such problem is hard to solve just by tamping.

(2) Periodic track alignment irregularity recognition model is established based on the geometric characteristics of multi-wave track alignment irregularity. After carrying out statistical analysis of certain line with this model, a total of $1.476 \mathrm{~km}$ lines with continuous multi-wave track alignment irregularities are identified, wherein 95\% quantile amplitude of continuous multi-wave track alignment irregularity is about $2.81 \mathrm{~mm}$, the variation of $95 \%$ quantile is $1.38 \mathrm{~mm}$, and shaking and poor light band have occurred in some sections.

(3) After comparing the simulation result of $200-250 \mathrm{~km} / \mathrm{h}$ track (comprehensive peak interval: $7 \mathrm{~m}$ and $10 \mathrm{~m}$ ), it is found that the peak interval of $10 \mathrm{~m}$ is more sensitive to the variation of multi-wave track alignment irregularity amplitude. In this paper, full consideration is given to operation safety and comfort, a certain redundancy is reserved and the control limits $(5 \mathrm{~mm}, 7 \mathrm{~mm}$ and $9 \mathrm{~mm})$ of continuous multi-wave track alignment irregularity of $200-250 \mathrm{~km} / \mathrm{h}$ ballasted track are provided.

(4) After comparing the simulation result of $300-350 \mathrm{~km} / \mathrm{h}$ track (comprehensive peak interval: $7 \mathrm{~m}$ and $10 \mathrm{~m}$ ), it is found that the peak interval of $10 \mathrm{~m}$ is more sensitive 
to the variation of multi-wave track alignment irregularity amplitude. In this paper, full consideration is given to operation safety and comfort, a certain redundancy is reserved and the control limits $(3 \mathrm{~mm}, 5 \mathrm{~mm}$ and $7 \mathrm{~mm})$ of continuous multi-wave track alignment irregularity of $300-350 \mathrm{~km} / \mathrm{h}$ ballasted track are provided.

\section{Acknowledgement}

Research is supported by the fund from China Academy of Railway Sciences (Number: 2019YJ161).

\section{References}

[1] Pombo J, Ambrosio J. An alternative method to include track irregularities in railway vehicle dynamic analyses. Nonlinear Dynamics, 2012, 68(1-2):161-176.

[2] Han QQ, Wu Y, Exploration for management value of track irregularity with multiple waves. Railway Standard Design, 2006, 33(8): 14-16.

[3] Wang ZJ, Liu B, Key technology on accurate adjusting of ballastless track of Wuhan-Guangzhou passenger-dedicated railway. Railway Engineering, 2010, 33(1): 1-6.

[4] Li DS, Yang F, Ma HJ, Analysis of impact of track periodic irregularity on common-span simply-supported beam bridge for high-speed railway. China Railway Science, 2020, 41(3): 59-67.

[5] Liu JZ, Diagnosis and evaluation method of track periodic geometric irregularity. Railway Engineering, 2016, (7): 1-5.

[6] Song GH, Gao MM, Cause analysis and control index research on periodic irregularity on simply-supported beam bridge for high-speed railway. Railway Engineering, 2019, 59(8): 1-4.

[7] European Committee for Standardization. Railway Applications - Track-Track Geometry Quality Part 5: Geometric Quality Levels: BS EN 13848-5. London: British Standards Institution, 2010.

[8] Network Rail. NRL2TRK001 Mod 11 Issue 8 Track geometry inspections and minimum actions. London: NW1 2ND, 2015.

[9] Final Rule Vehicle Track-Interaction Safety Standards. Federal Railroad Administration, part II, 2013.

[10] Liu CY, Guo AH, Cui BS, Time-frequency characteristic analysis of track irregularity of high-speed railway. Electronic Measurement Technology, 2009, 32(7): 29-32.

[11] $\mathrm{Hu} X Y$, Hou MR, Chang CY, et al, Research on the sensitive wavelength of track irregularity and its relationship with vehicle response based on the stationary-state and non-stationary-state vibration signal analysis. China Railway Science, 2012, 33(z1): 46-51.

[12] Zhang B, Liu XB, Ma S, et al, Recognition method for local deformation of high-speed railway subgrade based on time-frequency analysis. Railway Engineering, 2019, 59 (12): 95-98.

[13] Hou X, Zhang L. Saliency Detection: A Spectral Residual Approach. IEEE Conference on Computer Vision \& Pattern Recognition. IEEE, 2007.

[14] Pinnegar C. A new subclass of complex-valued s-transform windows. Signal Processing, 2006, 86(8): 2051-2055.

[15] Zeng Y, Jiang X and Fu LL, Analysis of longitudinal/alignment compound irregularity management limit of 30t heavy-load railway. Railway Standard Design, 2017, 61(12): 41-45.

[16] Cao XX, Yue P and Wang H, Analysis of dynamic modeling and stability of CRH2 vehicle based on UM. Journal of Lanzhou Jiaotong University, 2018, 37(3): 77-84, 92. 